\title{
Dependence of NMR Chemical Shifts upon CH Bond Lengths of a Methyl Group Involved in a Tetrel Bond
}

\author{
Steve Scheiner* \\ Department of Chemistry and Biochemistry \\ Utah State University \\ Logan, UT 84322-0300
}

*email: steve.scheiner@usu.edu

phone: 435-797-7419

\begin{abstract}
Four different Lewis acids that might participate in a tetrel bond with a nucleophile $\left(\mathrm{SEt}_{2} \mathrm{Me}^{+}, \mathrm{NMe}_{4}^{+}\right.$, $\mathrm{SMe}_{2}, \mathrm{NMe}_{3}$ ) are examined. The NMR chemical shifts of the methyl $\mathrm{C}$ and $\mathrm{H}$ atoms are calculated as the $\mathrm{CH}$ bond lengths are systematically stretched and contracted, in the absence of a base. The $\mathrm{C}$ shielding diminishes by roughly $2 \mathrm{ppm}$ for a stretch of $0.01 \AA$, while that of $\mathrm{H}$ drops by only $0.3 \mathrm{ppm}$. The deshieldings caused purely by the bond length changes are far too small to account for the amounts that are computed when the nucleophile is actually present.
\end{abstract}

keywords: noncovalent bond; M06-2X; Lewis acid, bond stretch 


\section{INTRODUCTION}

Following the earliest proposal that a $\mathrm{H}$ atom could serve as a bridge between two separate molecules in a H-bond (HB) came a flurry of activity intended to identify spectroscopic markers by which the presence of such a bond could be detected [1-4]. It was soon learned that the formation of a HB leads to a reduction in the bridging proton's NMR chemical shielding that was of large enough magnitude to serve as a signpost of its presence, as well as characteristic changes in the vibrational spectrum. The recent development of ideas concerning noncovalent bonds that are closely related to HBs, but wherein the bridging proton is replaced by one of numerous more electronegative atoms, as in halogen or pnicogen bonds, brings to the fore the issue as to whether NMR spectra can be used to identify the presence of these bonds as well. And indeed, there has been some success in this endeavor, where such bonds can in fact be detected, and further, that the extent of the chemical shifts might serve as a quantitative measure of their strength [5-16].

Perhaps the most recent newcomer to the set of H-bond analogues is the tetrel bond (TB). The lesser electronegativity of the tetrel atom $(\mathrm{T}=\mathrm{C}, \mathrm{Si}$, etc), as compared to its neighbors to its right in the periodic table, offers the possibility of a more intense $\sigma$-hole, and perhaps a stronger noncovalent bond as well. On the other hand, the four substituents normally surrounding a tetrel atom might obstruct the approach of a nucleophile, thereby impeding and/or weakening such a bond. Nonetheless, there has appeared in the literature a good deal of evidence that such tetrel bonds do form, along with the principles which govern their strength and the steric issues to which they are subject [7,17-27]. It is understood, for example, that tetrel bonds are strengthened by electron-withdrawing substituents, or by larger size of the tetrel atom, i.e. $\mathrm{C}<\mathrm{Si}<\mathrm{Ge}$. These bonds are far more common than earlier thought [28] within the context of proteins.

Given these principles, one might anticipate that the $\mathrm{CH}_{3}$ group might participate in only very weak tetrel bonds, if at all. Yet the literature is replete [13,29-31] with molecular structures which fit neatly into the fingerprint of a methyl tetrel bond. That is, the nucleophile B approaches the $\mathrm{R}-\mathrm{CH}_{3}$ methyl group along the extension of the R-C bond, and the interatomic C $\cdot$ B distance is shorter than the sum of their vdW atomic radii [31-34]. A recent review of crystal structures [35] has revealed a wealth of methyl tetrel bonds within an entire class of proteins.

And further, there is accumulating evidence that such methyl TBs are an integral component in the catalytic activity of various enzymes [36-38]. Because of the presence of the H substituents on a methyl group, it might be tempting to naively classify this interaction as a trifurcated $\mathrm{CH} \cdot \mathrm{B}$ H-bond, i.e. to assume that $\mathrm{B}$ interacts with the $\mathrm{H}$ rather than the $\mathrm{C}$ atom. However, tetrel and $\mathrm{H}$-bonds have different properties, and obey differing rules regarding their strength. As an example of where this distinction might be of even more importance, there is a class of enzymes whose principle purpose is the transfer of a methyl group from one entity to another. A first step in the activity of this enzyme is the approach of the methyl acceptor 
atom toward the methyl group. The transfer of the methyl group is facilitated by formation of a tetrel bond between the two, while a $\mathrm{CH} \cdot \mathrm{B} \mathrm{H}$-bond would not serve this function, and might even inhibit the reaction.

With this distinction in mind, it is important to have a means of determining whether a given system contains a tetrel or a $\mathrm{CH} \cdot \mathrm{B}$ HB. A prime tool in analyzing molecular structure and interactions is spectral in nature, most importantly vibrational and NMR. In order to provide some guidance as to the interpretation of this sort of experimental information in terms of TB vs $\mathrm{HB}$, a recent set of calculations [39] had considered the spectroscopic consequences of the formation of a TB involving a methyl group, and how these trends differ from what is observed when this same group is involved in a $\mathrm{CH}^{*} \mathrm{O} \mathrm{HB}$. It was found that formation of a TB caused a substantive deshielding of the methyl $\mathrm{C}$ atom, in amounts varying between 3 and 14 ppm, but the changes in the methyl protons were much more modest, typically less than 1 ppm. The spectroscopic consequences of a $\mathrm{CH} \cdot \cdot \mathrm{O} \mathrm{HB}$ were quite different, with greatly reduced deshielding of the $\mathrm{C}$ and increased deshielding of the $\mathrm{H}$ nucleus.

Given the fact that the formation of either a tetrel or a H-bond typically leads to a change of the T-H bond length, and with the presumption that the distance between the nuclei will have an effect upon their chemical shielding, it is natural to wonder if the former is the primary cause of the latter. In other words, the effects of the TB can be conceptually divided into two separate components, each of which is anticipated to affect the shielding around the nuclei. As a direct effect, the approach of the nucleophile will perturb the electronic structure of the Lewis acid, via polarization and charge transfer phenomena. More indirectly, the T-H bond lengths will change, which will in turn influence the nuclear shieldings. The disentangling of these two phenomena is not only of theoretical interest, but is also of importance in interpreting experimental structural and spectroscopic data. Resolution of this question would address, for example, the issue as to whether a measured chemical shift can be used to infer the T-H bond lengths. In a related practical question, how much of a $\mathrm{T}-\mathrm{H}$ bond extension or contraction would be required for the chemical shift to surpass a given measurement threshold?

The current work addresses this point specifically. A set of Lewis acids with a propensity to engage in methyl tetrel bonding are considered. In the absence of the perturbing effect of a nucleophile upon the electronic structure, the methyl $\mathrm{r}(\mathrm{CH})$ bond lengths are systematically stretched and contracted, and chemical shielding calculated for each such geometric configuration. In this way, the connection between NMR and geometric data is assessed directly and unambiguously for a set of diverse Lewis acids.

\section{SYSTEMS AND METHODS}

A methyl group was placed in the contexts of four different Lewis acids. The first of these is the cationic $\mathrm{S}(\mathrm{Et})_{2} \mathrm{Me}^{+}$system, which is a model of the sulfonium group that is an important element in a number of methyl transferase enzymes wherein the interaction between its transferring methyl group and a 
nucleophile is of some recent concern [37,38,40-42]. The effect of overall charge was examined by replacing this cation by the neutral $\mathrm{SMe}_{2}$ molecule. An alternate atom to which the methyl group might be covalently attached is $\mathrm{N}$. Both the cationic $\mathrm{N}(\mathrm{Me})_{4}{ }^{+}$and its neutral $\mathrm{N}(\mathrm{Me})_{3}$ analogue were thus also considered.

Calculations were carried out with the Gaussian-09 program suite [43], applying the M06-2X DFT functional within the framework of the aug-cc-pVDZ basis set. The geometry of each Lewis acid molecule was first fully optimized, with all positive frequencies confirming the presence of a minimum. Then the $\mathrm{r}(\mathrm{CH})$ bond lengths of a methyl group were changed in small uniform increments and decrements, with the remainder of the geometry frozen. The NMR chemical shifts of the $\mathrm{C}$ and $\mathrm{H}$ atoms of this methyl group were then computed for each such altered geometry.

\section{RESULTS}

The optimized geometries of the four potential methyl tetrel bonding species are displayed in Fig 1, along with their equilibrium $\mathrm{r}(\mathrm{CH})$ bond lengths. In most cases, all three $\mathrm{CH}$ bonds are of the same length, with the exception of the neutral $\mathrm{N}\left(\mathrm{CH}_{3}\right)_{3}$ where the $\mathrm{H}$ atom that lies anti to the $\mathrm{N}$ lone pair is a bit further from the $\mathrm{N}$ (by $0.013 \AA$ ) than are the other two protons which are positioned opposite a N-C bond. The chemical shielding of the $\mathrm{C}$ and $\mathrm{H}$ nuclei of the methyl groups in these four systems are reported in Table 1. (Also listed in the last row are the same quantities for the standard reference tetramethylsilane (TMS) so that the standard chemical shift $\delta$ may be derived.)

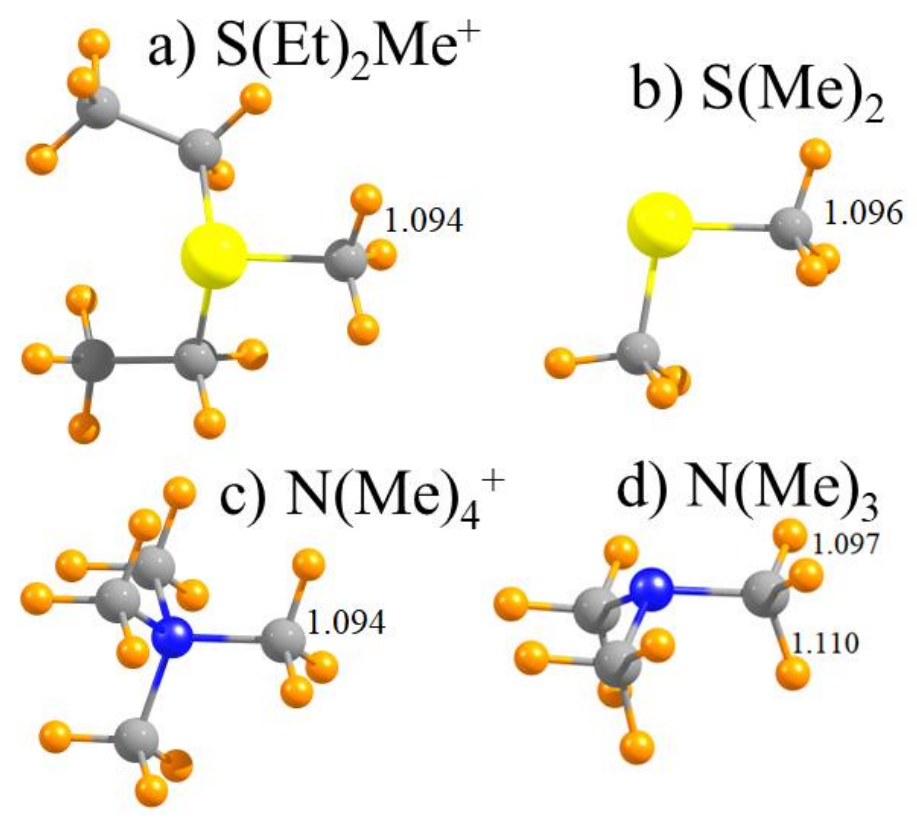

Fig 1. Geometries of systems examined, $\mathrm{CH}$ distances in $\AA$. 
Table 1. Calculated chemical shielding (ppm) of methyl $\mathrm{C}$ and $\mathrm{H}^{\mathrm{a}}$ atoms

\begin{tabular}{|l|l|l|}
\hline & C & H \\
\hline $\mathrm{S}(\mathrm{Et})_{2} \mathrm{Me}^{+}$ & 162.473 & 28.899 \\
\hline $\mathrm{S}(\mathrm{Me})_{2}$ & 172.482 & 29.622 \\
\hline $\mathrm{N}(\mathrm{Me})_{4}{ }^{+}$ & 135.954 & 28.481 \\
\hline $\mathrm{N}(\mathrm{Me})_{3}$ & 146.460 & 29.479 \\
\hline TMS & 194.149 & 31.621 \\
\hline
\end{tabular}

aaverage of three methyl protons

For each of these moieties, the $\mathrm{r}(\mathrm{CH})$ bond was stretched or contracted from its equilibrium length in fixed increments, and the chemical shift recalculated. The effect of each of these changes in bond length upon the chemical shielding is displayed in Fig $2 \mathrm{a}$ and $2 \mathrm{~b}$ for the $\mathrm{H}$ and $\mathrm{C}$ atoms, respectively. The black lines correspond to the systems with a central $\mathrm{S}$ atom, with $\mathrm{N}$ represented by red curves. Solid lines indicate cations and neutral molecules are shown by broken curves.

There are several trends which are common to all of the species, charged and neutral, containing either $\mathrm{S}$ or $\mathrm{N}$ as central atom. In the first place, stretching of the $\mathrm{C}-\mathrm{H}$ bonds leads to reduced shielding around both the $\mathrm{H}$ and $\mathrm{C}$ atoms (with the exception of the $\mathrm{N}\left(\mathrm{CH}_{3}\right)_{4}{ }^{+}$cation discussed below). The $\mathrm{C}$ shielding is far more sensitive than is the proton shielding. For example, a stretch of $\mathrm{r}(\mathrm{CH})$ by $0.20 \AA$ deshields the protons by roughly $0.6 \mathrm{ppm}$, while the $\mathrm{C}$ atom shielding drops by some $4 \mathrm{ppm}$. If one were to fit the curves in Fig 2 to a straight line, the slope of the $\mathrm{H}$ shielding is $-28 \mathrm{ppm} / \AA$, whereas the $\mathrm{C}$ shielding drops by some 200 ppm for a 1 A elongation.
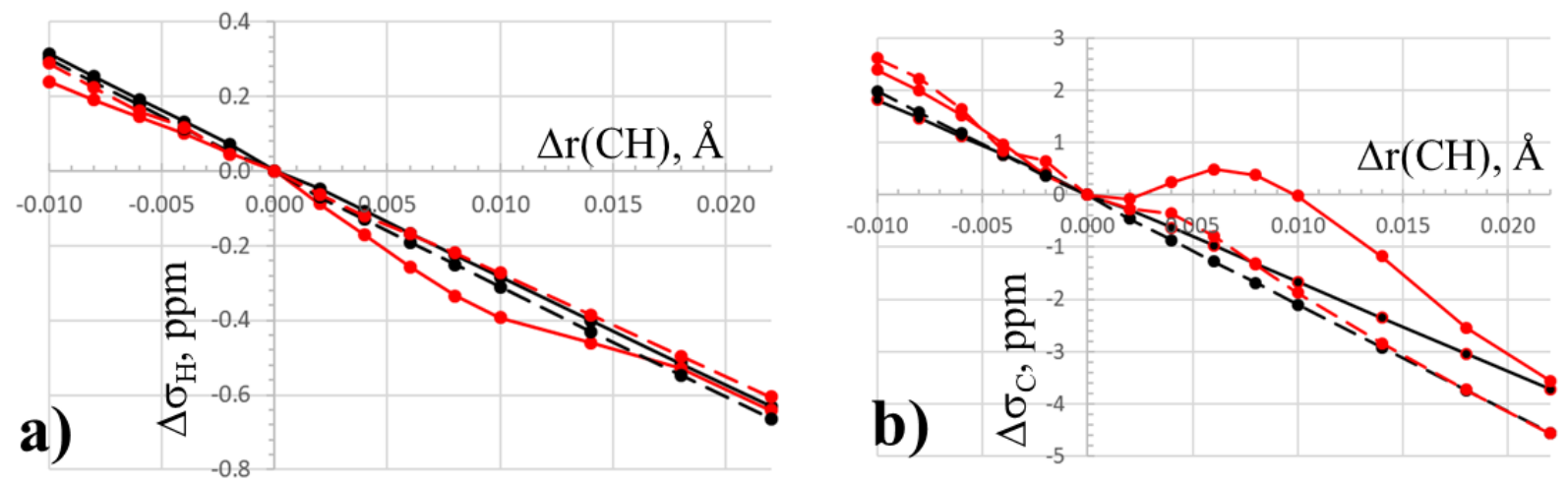

Fig 2. Changes in chemical shielding of a) $\mathrm{H}$ and b) $\mathrm{C}$ nuclei of methyl groups caused by contraction and stretching of methyl $\mathrm{CH}$ lengths from equilibrium. Black curves refer to species with $\mathrm{S}$ central atom and red to $\mathrm{N}$. Solid and broken curves indicate cationic and neutral species, respectively. 
It is notable that, with the exception of $\mathrm{N}\left(\mathrm{CH}_{3}\right)_{4}{ }^{+}$, the data for the other three systems are fairly uniform from one to the next, regardless of whether the species is charged or neutral, or whether $\mathrm{S}$ or $\mathrm{N}$ serves as central atom. The curves are also quite close to linear relations between $\Delta \sigma$ and $\Delta \mathrm{r}(\mathrm{CH})$. For example, the correlation coefficient for these two parameters is between 0.99 and 1.00 for $\Delta \sigma_{H}$ for each system. The same is true for $\Delta \sigma_{\mathrm{C}}$, with the exception of $\mathrm{N}\left(\mathrm{CH}_{3}\right)_{4}{ }^{+}$, where this quantity drops to 0.93 . The poorer correlation in the latter case is connected with an increase in the $\mathrm{C}$ chemical shielding for $\mathrm{r}(\mathrm{CH})$ stretches from equilibrium between 0.004 and $0.010 \AA$, as may be seen by the behavior of the solid red curve in Fig 2b. This greater shielding of $\mathrm{C}$ is also mirrored by a larger decrease in the $\mathrm{H}$ shielding over this same range, cf Fig 2a.

With an eye on the trends in Fig 2 it is possible to determine the importance of the $\mathrm{r}(\mathrm{CH})$ changes caused by TB formation upon the NMR spectra. Previous calculations $[24,44,45]$ have shown that the $\mathrm{CH}$ bond lengths of methyl tetrel bonds change by less than $5 \mathrm{m \AA}$, stretched in some cases and contracted in others. The second column of Table 2 shows these $\mathrm{CH}$ bond length changes in a set of specific [39] tetrelbonded systems. This bond change leads to a predicted change in the chemical shielding of both $\mathrm{H}$ and $\mathrm{C}$ using Fig 2 as a guide, a change which is due solely to the elongation/contraction of the $\mathrm{CH}$ bond in the absence of the nucleophile. This prediction is reported in the $\Delta \mathrm{r}$ columns of Table 2 . The succeeding columns display the shielding change actually calculated [39] for the full system, including the nucleophile and its perturbation of the Lewis acid wave function.

Table 2. Methyl $\mathrm{CH}$ bond length changes in various tetrel-bonded systems, along with calculated changes in proton chemical shielding (ppm). $\Delta \mathrm{r}$ refers to the shielding change predicted solely on the basis of stretch or contraction of $\mathrm{CH}$ bond length, and full corresponds to that calculated in presence of nucleophile.

\begin{tabular}{|l|c|r|r|r|r|}
\hline & $\Delta \mathrm{r}(\mathrm{CH}), \mathrm{m} \AA$ & \multicolumn{2}{|c|}{$\Delta \sigma(\mathrm{H})$} & \multicolumn{2}{c|}{$\Delta \sigma(\mathrm{H})$} \\
\hline & & \multicolumn{1}{|c|}{$\Delta \mathrm{r}$} & \multicolumn{1}{c|}{ full } & \multicolumn{1}{c|}{$\Delta \mathrm{r}$} & \multicolumn{1}{c|}{ full } \\
\hline $\mathrm{SMe}_{3}{ }^{+.} \cdot \mathrm{NH}_{3}$ & -1.5 & 0.04 & -0.35 & 0.30 & -5.79 \\
\hline $\mathrm{SMe}_{3}{ }^{+\cdot .} \mathrm{OH}_{2}$ & -1.0 & 0.03 & -0.28 & 0.20 & -4.66 \\
\hline $\mathrm{SMe}_{3}{ }^{+\cdot .} \mathrm{OCH}_{3}^{-}$ & +1.5 & -0.04 & -1.60 & -0.30 & -13.85 \\
\hline $\mathrm{SMe}_{2} \cdot \cdot \mathrm{OH}^{-}$ & -3.0 & 0.08 & -1.31 & 0.60 & -7.42 \\
\hline $\mathrm{SMe}_{2} \cdot \cdot \mathrm{HCOO}^{-}$ & -1.5 & 0.04 & -0.74 & 0.30 & -7.13 \\
\hline $\mathrm{NMe}_{4}{ }^{+\cdot \cdot} \mathrm{OCHNH}_{2}$ & -1.5 & 0.04 & -0.43 & 0.30 & -2.71 \\
\hline
\end{tabular}

It is immediately evident that removal of the nucleophile, leaving behind only its effect on the $\mathrm{CH}$ bond lengths, leads to results vastly different than in the full dimer. In the first place, the magnitudes of the shielding changes caused purely by bond length changes are much smaller than the full values. Secondly, their signs are even different in a number of cases. The $\mathrm{SMe}_{3}{ }^{+\cdot \cdot} \mathrm{NH}_{3}$ system is a case in point: the $1.5 \mathrm{~m} \AA$ 
contraction of the methyl $\mathrm{CH}$ bonds would lead to increased shielding on the $\mathrm{H}$ and $\mathrm{C}$ atoms of 0.04 and $0.30 \mathrm{ppm}$, respectively. But the electronic perturbations caused by the nucleophile in the full dimer predict reduced shielding, by 0.35 and $5.79 \mathrm{ppm}$ for $\mathrm{H}$ and $\mathrm{C}$, respectively.

One can imagine another scenario wherein for each particular value of $\mathrm{r}(\mathrm{CH})$ the remainder of the geometry of the molecule is allowed to adjust, rather than being held frozen. When the geometry of the $\mathrm{S}(\mathrm{Et})_{2} \mathrm{Me}^{+}$system was accordingly reoptimized in this fashion, the results were barely changed. The $\mathrm{H}$ shielding was not affected by the reoptimization at all, while the $\mathrm{C}$ shift was only slightly weaker, reduced by $8 \%$. In calculations such as these, there is always the question as to whether the data are sensitive to the choice of basis set. When these calculations were repeated for the $\mathrm{S}(\mathrm{Et})_{2} \mathrm{Me}^{+}$system using the larger augcc-pVTZ basis set, there was no change observed in the increment caused in the ${ }^{1} \mathrm{H}$ chemical shift by stretching or compressing the $\mathrm{r}(\mathrm{CH})$ bond. The ${ }^{13} \mathrm{C}$ shift was only slightly affected, with the sensitivity of shielding to bond length increasing by only $7 \%$.

Finally, one may wonder about how the shielding of the $\mathrm{C}$ and $\mathrm{H}$ atoms are affected by a contraction or stretch of the bond between $\mathrm{C}$ and the heavy atom to which it is attached, rather than to the H. Again using the $\mathrm{S}(\mathrm{Et})_{2} \mathrm{Me}^{+}$cation as a prototype, the dependence of the $\mathrm{H}$ shielding upon the $\mathrm{r}(\mathrm{CS})$ bond length was reduced by an order of magnitude when compared to its sensitivity to $\mathrm{r}(\mathrm{CH})$. That is, a $\mathrm{CS}$ bond stretch of $0.01 \AA$ A lowered the $\mathrm{H}$ shielding by $0.03 \mathrm{ppm}$, as compared to a reduction of $0.3 \mathrm{ppm}$ for an equivalent elongation of $\mathrm{r}(\mathrm{CH})$. The $\mathrm{C}$ shielding, on the other hand, is affected by a CS stretch in roughly the same measure as by a $\mathrm{CH}$ stretch. Whereas a stretch of $\mathrm{C}-\mathrm{H}$ by $0.01 \AA$ lowers the $\mathrm{C}$ shielding by $1.66 \mathrm{ppm}$, the same elongation of $\mathrm{r}(\mathrm{CS})$ reduces $\sigma$ by the slightly smaller amount of $1.40 \mathrm{ppm}$.

In summary, the chemical shielding of both the $\mathrm{C}$ and $\mathrm{H}$ nuclei of a methyl group is inversely proportional to the $\mathrm{r}(\mathrm{C}-\mathrm{H})$ bond length. The shielding rises if this bond is contracted and is reduced as the bond is stretched. The shielding on the $\mathrm{C}$ atom is more sensitive to this elongation than is $\mathrm{H}$. A $0.01 \AA$ stretch in $\mathrm{r}(\mathrm{CH})$ reduces the $\mathrm{C}$ shielding by some $2 \mathrm{ppm}$ while that of $\mathrm{H}$ drops by only $0.3 \mathrm{ppm}$. Although there is some sensitivity to the particular entity on which the methyl group is situated, these trends are fairly consistent, extending to both neutral and cationic systems, as well as to chemical environments, whether the methyl group is bonded to $\mathrm{S}$ or $\mathrm{N}$. The effects of these bond length changes upon the chemical shielding are fairly small when compared to those engendered by the participation of the methyl group in a noncovalent interaction, such as a tetrel bond, and not always of the same sign. It is concluded that the observed NMR spectral features cannot be directly attributed to changes in methyl $\mathrm{CH}$ bond length caused by noncovalent bond formation. 
It is stressed finally that the dependence of nuclear shielding upon $\mathrm{CH}$ bond length exhibited in Fig 2, is independent of the particular phenomenon that might be causing these bonds to stretch. That is, these trends would be just as applicable to a H-bond, or indeed any other noncovalent bond, as to a tetrel bond. 


\section{REFERENCES}

[1] M.L. Huggins, Angew. Chem., Int. Ed. Engl. 10 (1971) 147.

[2] M.D. Joesten, L.J. Schaad, Hydrogen Bonding, Marcel Dekker, New York, 1974.

[3] P. Schuster, G. Zundel, C. Sandorfy, The Hydrogen Bond. Recent Developments in Theory and Experiments. North-Holland Publishing Co., Amsterdam, 1976.

[4] P. Schuster, Hydrogen Bonds, Springer-Verlag, Berlin, 1984.

[5] M. Iwaoka, H. Komatsu, T. Katsuda, S. Tomoda, J. Am. Chem. Soc. 126 (2004) 5309.

[6] M.T. Messina, P. Metrangolo, W. Panzeri, E. Ragg, G. Resnati, Tetrahedron Lett. 40 (1998) 9069.

[7] K. Vojinović, L.J. McLachlan, S.L. Hinchley, D.W.H. Rankin, N.W. Mitzel, Chem. Eur. J. 10 (2004) 3033.

[8] M.G. Sarwar, B. Dragisic, L.J. Salsberg, C. Gouliaras, M.S. Taylor, J. Am. Chem. Soc. 132 (2010) 1646.

[9] D. Hauchecorne, B.J. van der Veken, W.A. Herrebout, P.E. Hansen, Chem. Phys. 381 (2011) 5.

[10] J.E. Del Bene, G. Sanchez-Sanz, I. Alkorta, J. Elguero, Chem. Phys. Lett. 538 (2012) 14.

[11] M.D. Esrafili, F. Mohammadian-Sabet, Chem. Phys. Lett. 638 (2015) 122.

[12] P. Chaudhary, J.T. Goettel, H.P.A. Mercier, S. Sowlati-Hashjin, P. Hazendonk, M. Gerken, Chem. Eur. J. 21 (2015) 6247.

[13] S.A. Southern, D.L. Bryce, J. Phys. Chem. A 119 (2015) 11891.

[14] L. Turunen, A. Peuronen, S. Forsblom, E. Kalenius, M. Lahtinen, K. Rissanen, Chem. Eur. J. 23 (2017) 11714.

[15] V. Thangavadivale, P.M. Aguiar, N.A. Jasim, S.J. Pike, D.A. Smith, A.C. Whitwood, L. Brammer, R.N. Perutz, Chem. Sci. 9 (2018) 3767.

[16] B. Watson, O. Grounds, W. Borley, S.V. Rosokha, Phys. Chem. Chem. Phys. 20 (2018) 21999.

[17] A. Bauzá, T.J. Mooibroek, A. Frontera, Angew. Chem. Int. Ed. 52 (2013) 12317.

[18] A.R. Rossi, J.M. Jasinski, Chem. Phys. Lett. 169 (1990) 399.

[19] S. Scheiner, Molecules 23 (2018) 1147.

[20] M. Hagemann, R.J.F. Berger, S.A. Hayes, H.-G. Stammler, N.W. Mitzel, Chem. Eur. J. 14 (2008) 11027.

[21] M. Marín-Luna, I. Alkorta, J. Elguero, Theor. Chem. Acc. 136 (2017) 41.

[22] S.J. Grabowski, W.A. Sokalski, ChemPhysChem. 18 (2017) 1569.

[23] W. Zierkiewicz, M. Michalczyk, S. Scheiner, Phys. Chem. Chem. Phys. 20 (2018) 8832.

[24] S. Scheiner, J. Phys. Chem. A 121 (2017) 5561.

[25] X. García-Llinás, A. Bauzá, S.K. Seth, A. Frontera, J. Phys. Chem. A 121 (2017) 5371.

[26] S. Scheiner, J. Phys. Chem. A 122 (2018) 2550.

[27] W. Zierkiewicz, M. Michalczyk, S. Scheiner, Molecules 23 (2018) 1416.

[28] V.R. Mundlapati, D.K. Sahoo, S. Bhaumik, S. Jena, A. Chandrakar, H.S. Biswal, Angew. Chem. Int. Ed. (in press) 10.1002/anie.201811171.

[29] S.P. Thomas, M.S. Pavan, T.N. Guru Row, Chem. Commun. 50 (2014) 49.

[30] A. Bauzá, T.J. Mooibroek, A. Frontera, The Chemical Record 16 (2016) 473.

[31] A. Bauzá, A. Frontera, Cryst. 6 (2016) 26.

[32] D. Mani, E. Arunan, Phys. Chem. Chem. Phys. 15 (2013) 14377.

[33] Q.-Z. Li, H.-Y. Zhuo, H.-B. Li, Z.-B. Liu, W.-Z. Li, J.-B. Cheng, J. Phys. Chem. A 119 (2015) 2217.

[34] J.E. Del Bene, I. Alkorta, J. Elguero, Chem. Phys. Lett. 655-656 (2016) 115.

[35] R. Trievel, S. Scheiner, Molecules (2018) (in press).

[36] M.B. Poulin, J.L. Schneck, R.E. Matico, P.J. McDevitt, M.J. Huddleston, W. Hou, N.W. Johnson, S.H. Thrall, T.D. Meek, V.L. Schramm, Proc. Nat. Acad. Sci., USA 113 (2016) 1197.

[37] R.J. Fick, M.C. Clay, L. Vander Lee, S. Scheiner, H. Al-Hashimi, R.C. Trievel, Biochem. 57 (2018) 3733. 
[38] J. Zhang, J.P. Klinman, J. Am. Chem. Soc. 138 (2016) 9158.

[39] S. Scheiner, J. Phys. Chem. A 122 (2018) 7852.

[40] M.L. Ludwig, R.G. Matthews, Ann. Rev. Biochem. 66 (1997) 269.

[41] H.L. Schubert, R.M. Blumenthal, X. Cheng, Trends Biochem. Sci. 28 (2003) 329.

[42] A.S. Byer, H. Yang, E.C. McDaniel, V. Kathiresan, S. Impano, A. Pagnier, H. Watts, C. Denler, A.L. Vagstad, J. Piel, K.S. Duschene, E.M. Shepard, T.P. Shields, L.G. Scott, E.A. Lilla, K. Yokoyama, W.E. Broderick, B.M. Hoffman, J.B. Broderick, J. Am. Chem. Soc. 140 (2018) 8634.

[43] M.J. Frisch, G.W. Trucks, H.B. Schlegel, G.E. Scuseria, M.A. Robb, J.R. Cheeseman, G. Scalmani, V. Barone, B. Mennucci, G.A. Petersson, H. Nakatsuji, M. Caricato, X. Li, H.P. Hratchian, A.F. Izmaylov, J. Bloino, G. Zheng, J.L. Sonnenberg, M. Hada, M. Ehara, K. Toyota, R. Fukuda, J. Hasegawa, M. Ishida, T. Nakajima, Y. Honda, O. Kitao, H. Nakai, T. Vreven, J. Montgomery, J. A., J.E. Peralta, F. Ogliaro, M. Bearpark, J.J. Heyd, E. Brothers, K.N. Kudin, V.N. Staroverov, R. Kobayashi, J. Normand, K. Raghavachari, A. Rendell, J.C. Burant, S.S. Iyengar, J. Tomasi, M. Cossi, N. Rega, J.M. Millam, M. Klene, J.E. Knox, J.B. Cross, V. Bakken, C. Adamo, J. Jaramillo, R. Gomperts, R.E. Stratmann, O. Yazyev, A.J. Austin, R. Cammi, C. Pomelli, J.W. Ochterski, R.L. Martin, K. Morokuma, V.G. Zakrzewski, G.A. Voth, P. Salvador, J.J. Dannenberg, S. Dapprich, A.D. Daniels, O. Farkas, J.B. Foresman, J.V. Ortiz, J. Cioslowski, D.J. Fox, Gaussian 09, Wallingford, CT, 2009.

[44] S. Scheiner, J. Phys. Chem. A 119 (2015) 9189.

[45] V.d.P.N. Nziko, S. Scheiner, Phys. Chem. Chem. Phys. 18 (2016) 3581. 